\title{
Perspectivas de professores do ensino fundamental sobre a formação continuada - a relação saber e prática transformadora: um estudo de caso $^{\mathrm{i}, \mathrm{ii}}$
}

\section{Perspectives of elementary teachers on continuous training - the relationship of knowledge and transforming practice: a case study}

\author{
Katharine Moucherek ${ }^{1 *}$, Fátima Pereira² Amélia Lopes $^{3}$
}

\section{RESUMO}

O artigo objetiva problematizar a percepção que professores do Ensino Fundamental de escolas públicas da cidade brasileira de São Luís-Maranhão, têm sobre a formação continuada com base numa concepção (re)construtiva da relação do saber com uma prática que se almeja transformadora, considerando suas perspectivas. O marco teórico tem como fundamento obras de Charlot e de autores que se alinham e/ou complementam seu pensamento, como: Gatti, Pereira, Lopes, Tardif, Ferreira e outros. São apresentados excertos da pesquisa qualitativa, por meio de estudo de caso realizado com quatro professores do ensino da língua inglesa, com base em entrevista semiestruturada. Os resultados foram sistematizados em eixos temáticos e em categorias de análise. Conclui-se que o processo de formação continuada promove avanços na relação saber e prática, embora ainda não oportunize a plena emancipação profissional.

Palavras-chave: Formação continuada; Ensino Fundamental; Relação saber e prática.

\begin{abstract}
The article aims to problematize the perception that elementary school teachers from public schools in the Brazilian city of São Luís-Maranhão have about continuing education based on a (re)constructive conception of the relationship of knowledge with a practice that aims to transform itself, considering its perspectives. The theoretical framework is based on works by Charlot and authors who align with and/or complement his thinking, such as: Gatti, Pereira, Lopes, Tardif, Ferreira and others. Extracts from the qualitative research are presented, through a case study carried out with four English language teachers, based on a semi-structured interview. The results
\end{abstract}

\footnotetext{
${ }^{1}$ Doutoranda em Ciências da Educação na Faculdade de Psicologia e de Ciências da Educação na Universidade do Porto.

* katharine.moucherek@gmail.com

https://orcid.org/0000-0001-7479-5983

${ }^{2}$ Professora Associada com Agregação CIIE - Centro de Investigação e Intervenção Educativas, Faculdade de Psicologia e de Ciências da Educação da Universidade do Porto, Portugal.

fpereira@fpce.up.pt

https://orcid.org/0000-0003-1107-7583

${ }^{3}$ Professora Catedrática CIIE - Centro de Investigação e Intervenção Educativas, Faculdade de
Psicologia e de Ciências da Educação da Universidade do Porto, Portugal.
amelia@ fpce.up.pt
https://orcid.org/0000-0002-5589-5265
} 
were systematized in thematic axes and analysis categories. It is concluded that the continuing education process promotes advances in the relationship between knowledge and practice, although it does not yet provide full professional emancipation.

Keywords: Continuing training; Elementary School; Knowledge and practice relationship.

\section{INTRODUÇÃO}

A temática formação de professores e, mais especificamente, a formação continuada tem se constituído foco de crescentes pesquisas, sobretudo nas últimas décadas, assinalando a complexidade do desenvolvimento profissional docente. Destacase que as realidades local e global vêm sofrendo constantes transformações a ponto de exigir dos professores novas habilidades e competências específicas como forma de enfrentamento aos desafios que se apresentam.

A educação tem sido crescentemente um campo de "incertezas", o que pressupõe um olhar mais acurado para a questão formativa dos professores. O processo de formação continuada encontra-se contextualizado no que historicamente se tem construído acerca da docência, sua constituição como profissão, seus saberes e fazeres, a busca pelo reconhecimento social e por condições profissionais adequadas de trabalho. Segundo Gatti (2009), a formação de professores, incluindo a formação continuada vem se constituindo em processos de construção, rupturas, reconstrução, descompassos, entre tantos movimentos, sobretudo no Brasil.

Na problemática da formação continuada de professores encontra-se uma questão que merece um olhar mais acurado: a do saber e sua relação com a prática docente. Por meio das contribuições de Charlot $(2000,2005,2008,2014)$ busca-se elementos à superação da compreensão tradicional do fracasso escolar, ao abordar outros enfoques que abrangem o aprender. Charlot (2000) afirma não haver um saber, senão para um sujeito, sendo que este saber se organiza conforme suas relações internas, pessoais. Defende, ainda, que a ideia de saber implica a de sujeito, de atividade do sujeito, de mobilização para o aprender a partir da relação deste com ele mesmo, com o mundo e com os outros. Tais referenciais atrelam-se às dimensões epistêmica, identitária e social.

O processo formativo docente, incluindo a formação continuada, é um reflexo das transformações no mundo do trabalho que, por sua vez, se relacionam com transformações econômicas e socioculturais mais abrangentes. Tais estudos alertam para a influência de racionalidades exteriores ao campo da formação e da educação que 
condicionam as práticas e as políticas de formação. Sendo assim, a necessidade da (re) construção conceitual do saber e do fazer docente implica incluir proposições acerca do próprio conhecimento e de como ele é concebido e ensinado.

Marques et al. (2020, p. 97695) destacam alguns conceitos acerca da construção do saber e do fazer docente, tais como:

A profissionalização docente, discute sobre os caminhos e entraves porque passam os professores em busca do reconhecimento enquanto categoria profissional, buscando superar entraves como preconceitos do imaginário social, como exemplo, o preconceito com o fazer do professor - que não trabalha - pois ensinar não é considerado trabalho - nessa perspectiva do imaginário, $[\ldots]$

A discussão sobre os desafios da profissionalização docente, perpassam por preconceitos, especificidades da profissão docente, lutas para garantia da atividade docente exercida a partir de um corpus de saberes inerentes aos professores, ao exercício da profissão, amparados em competências e habilidades específicas - arcabouço teórico metodológico.

$[\ldots]$.

O saber docente, traz à luz as especificidades da docência no sentido de legitimar a prática docente. Tardif (2014) e Ramalho (2004) colocam os saberes experienciais e a legislação como objetos da formação profissional que para serem reconhecidos passam por certa dose de "violência simbólica".

Segundo Marques et al. (2020), a legislação e os saberes da experiência estão em lados opostos. Os autores recomendam que o ponto de partida deveria ser o saber, a experiência do professor, para traçar o plano de ensino/aprendizagem, reconhecendo assim, os saberes docentes e não a idealização legislativa. Ou seja, não se deve legislar $a$ priori, sem considerar o chão da escola - a prática docente.

Recorre-se às contribuições de: Tardif (2002); Pereira (1999); Ferreira (2009); Lopes (2001); Schön (1995); Alarcão (1996, 2001); Korthagen (2017); Zeichner (1993, 2008); Flores (2005, 2017); Forte e Flores (2012, 2014); Day (2001); Correia (2005), entre outros, para elucidar pontos relativos ao desenvolvimento profissional docente e da construção de identidades ao papel da formação inicial, da aprendizagem profissional ao longo da carreira, da prática reflexiva e do trabalho colaborativo em contextos de formação continuada. Os autores apontam, por exemplo, a necessidade de uma abordagem da formação continuada como aspecto inerente à aprendizagem profissional do professor e seu desenvolvimento ao longo do tempo, ressaltando refletir sobre esta formação não pelo viés de uma concepção deficitária, mas, sim, enquanto uma condição da profissionalização docente. 
Assim, ao considerar as perspectivas dos professores do Ensino Fundamental de escolas públicas, este estudo objetiva compreender as suas concepções de formação continuada e a experiência profissional que as sustentam. Procura-se problematizar a formação continuada de professores considerando uma perspectiva (re)construtiva, a partir do cotidiano escolar, da relação do saber com uma prática que se almeja transformadora.

\section{PERCURSO METODOLÓGICO}

Os dados deste artigo são oriundos de pesquisa desenvolvida no âmbito do Programa de Pós-Graduação em Ciências da Educação, nível Doutorado, da Faculdade de Psicologia e de Ciências da Educação da Universidade do Porto, Portugal.

A primeira parte da pesquisa foi de cunho bibliográfico e documental, complementada pela pesquisa qualitativa com base em um estudo de caso. O campo investigado constituiu-se em sete escolas públicas localizadas na cidade de São Luís, Maranhão, Brasil, das quais quatro são, agora, objeto de estudo deste artigo, representadas cada uma delas por um profissional docente da Língua Inglesa, pelas similaridades e singularidades por eles expressas.

Para a realização desta investigação, a pesquisadora obteve o consentimento da Superintendência da área de Ensino Fundamental da Secretaria Municipal da Educação de São Luís, Maranhão, além da anuência do gestor e dos profissionais de cada escola. Destaca-se também que as informações obtidas pelos participantes da pesquisa foram submetidas às normas e autorizadas por parte de cada um deles, conforme Termo de Consentimento Livre e Esclarecido. Um dos critérios de inclusão foi $o$ da representatividade das escolas por núcleo regional da cidade de São Luís.

Ressalta-se a opção pelo estudo de caso com objetivos interpretativos, uma vez que estão voltados à compreensão da ação educativa (AMADO, 2014; BOGDAN BIKLEN, 1994). Tendo como premissa que o conhecimento é construído com os sujeitos, justifica-se, então, a escolha do método, em abordagem que integra uma perspectiva biográfica (GOODSON, 2007). Os sujeitos eram professores de escolas públicas do Ensino Fundamental entre o $1^{\circ}$ e o $9^{\circ}$ ano. Foram realizadas entrevistas semiestruturadas (de um total de trinta), de cunho biográfico, das quais quatro são destacadas com professores que lecionam na área da Língua Inglesa. Quanto à formação acadêmica, os professores possuem Licenciatura em Letras, com habilitação para o ensino da Língua 
Inglesa e cursos de especialização. A formação inicial está entre os anos de 1996 e 2005. O tempo de trabalho na profissão varia entre 11 e 33 anos. A faixa etária varia entre 40 e 50 anos. Os nomes atribuídos são fictícios - Joshua, Victória, Maria Fernanda, Bibinha e foram escolhidos pelos próprios professores.

As narrativas foram alinhadas em eixos temáticos e em categorias (LIMA; PACHECO, 2006; MINAYO, 2011). Foram elencados cinco eixos temáticos: A construção do saber numa perspectiva biográfica; A construção do saber e a colaboração profissional; A relação com o saber e a transformação da prática; A relação com o saber e o desenvolvimento profissional; A dimensão tempo na relação com o saber. Foram correlacionadas aos eixos temáticos, quatro categorias: Reflexividade, Profissionalidade, Contextualidade e Colaboratividade.

\section{PERSPECTIVAS DOS PROFESSORES SOBRE SUA RELAÇÃO COM O SABER}

Considerando a teorização de Charlot (2000) percebeu-se destaque nas falas dos professores quanto à dimensão social, tanto nas interações entre pares, quanto com os alunos, a permear o cotidiano escolar. $\mathrm{O}$ saber se torna significativo para alunos e professores, na medida em que responde a uma ou mais de suas necessidades ou potencialidades, especialmente, no contexto local. No que diz respeito às interações com os alunos, há consenso entre os professores sobre a colaboração dos estudantes na dinâmica de construção do saber. Surge, ainda, um conceito inesperado: o aluno-âncora.

\footnotetext{
"Aquele aluno que ajuda. Sabe aqueles alunos que o tempo inteiro são grandes âncoras para a gente? [...] Eles entendem e trazem a turma. Por exemplo, todo mundo está bagunçando e eles mesmos intervêm: "ô gente,[...]Ele está falando alguma coisa importante! Vocês não estão prestando atenção?" Então, é, esse o aluno-âncora (Joshua).
}

A interação entre pares aparece sob uma perspectiva de esperança e desejo, acompanhada da ausência de um espaço e de um tempo formal significativo para o movimento de colaboração entre os professores. Segundo Lopes (2001, p. 365), esse sentimento de pertencimento a um grupo social e emocionalmente interdependente cria um ambiente em que professores "aceitam a responsabilidade coletiva pelo trabalho da escola." Os professores revelaram profunda relação com o saber, sobretudo ao expressarem aspectos relacionados à dimensão identitária, como questões da subjetividade, de sua história de vida, de sua individualidade e, em especial, a relação da 
construção do saber com sua autoimagem. Na visão de Charlot (2000), é por meio da relação com o aprender que o sujeito assume sua condição humana, humaniza-se, singulariza-se e socializa-se, tornando-se único. Fundamenta ainda que o aprender pressupõe apropriar-se de práticas relacionais humanas e de questões sobre o sentido da vida na perspectiva individual e coletiva. Na percepção dos professores, encontrar com colegas e alunos que queiram trabalhar em colaboração é motivo de satisfação pessoal e profissional. É patente, nos relatos, o saber como parte fundamental da identidade profissional e pessoal docente. A relação com o saber por eles expressa é profunda e significativa.

A dimensão epistêmica da relação com o saber é, de igual forma, considerada na história desses professores. Expressaram a necessidade de constante reflexão sobre os fundamentos epistemológicos nos quais o saber é construído. Reforçaram a importância da atividade intelectual, do problematizar a realidade à luz dos conceitos teóricos já construídos, para sistematizá-los, validá-los e/ou inová-los.

A construção do saber pressupõe trajetória a ser trilhada pelos professores, atrelada a uma postura questionadora e reflexiva (CHARLOT, 2000). Os professores revelaram que a relação com o saber está implicada nas suas vivências como aprendentes: "Porque eu, como aluno, não sou fácil, não. Eu inquiro muito. 'Mas, por que é assim? Por que não pode ser diferente?' [...]. E eu ficava chateado quando o professor reclamava de mim. Mas, eu continuava. Porque eu queria aprender...” (Joshua).

\section{UM OLHAR ANALÍTICO SOBRE A PESQUISA}

As bases epistemológicas defendidas por Charlot (2000) permitem-nos definir eixos temáticos e categorias a sustentar o debate no que tange à relação do saber com a prática no processo de formação continuada. Para tanto, a perspectiva analítica desta investigação apoia-se em cinco eixos temáticos e em quatro categorias.

\section{EIXO TEMÁTICO 1. A construção do saber numa perspectiva biográfica}

Partiu-se do ponto de como cada professor passou a se identificar com a docência como profissão e de como foi compreendendo a construção da relação saber e docência.

A professora Maria Fernanda considerou que começou a se identificar com a profissão e a construir o saber pela docência desde a infância: “A minha mãe era 
professora. A minha avó, também. [...]. Desde criança eu sempre gostei de brincar de dar aula. Sempre amei dar aula [...].” A professora Victória destacou a dinâmica de construção do saber entre pares, quando, ainda era estudante nos anos iniciais: "Desde criança, eu já dava aula para os meus amiguinhos na escola. A gente tinha aula pela manhã e eu dava aula para eles no contraturno [...]." O professor Joshua deu ênfase ao saber como conjunto de princípios e valores que aprendeu com a família e considera este seu diferencial na profissão: "Eu chegava no horário, não faltava nunca. Era o exemplo do meu pai. Ele nunca foi de faltar. [...] foi muito trabalhador[...]".

A construção do saber docente, segundo os professores, os remete à infância, à família e à vida escolar. Seja porque tiveram experiências significativas com alguns, ou porque tiveram dificuldades que lhes impulsionaram na busca por superação. Toda interação tem, potencialmente, a capacidade de subsidiar a construção de novas aprendizagens. Ao serem evocadas memórias de vida que remetem a diferentes espaços e tempos, a construção do saber para a docência passa a ser vista como um processo mais amplo, complexo e, ao mesmo tempo, subjetivo. Os professores reconheceram a importância das intervenções educativas no âmbito escolar e acadêmico. Entretanto, revelaram especial atenção aos movimentos individuais internos de construção do saber. A dinâmica dessa construção está imbricada, sobretudo, a fatores subjetivos, pessoais que expressam a relação da identidade com o saber.

\section{EIXO TEMÁTICO 2. A construção do saber e a colaboração profissional}

No que se refere às fontes de colaboração, os relatos identificaram como pares, em primeiro lugar, os colegas de trabalho (na mesma organização ou em organizações diferentes), depois, amigos professores, familiares professores e, até mesmo, professores desconhecidos, por meio de grupos de discussões virtuais, blogs ou redes sociais. Outra fonte foram os alunos, especialmente em situações de resolução de problemas, podendo surgir, como já mencionado, os "alunos-âncora". Há também ações colaborativas vivenciadas com a comunidade, e em espaços como igreja, projetos sociais etc.

Dentre os aspectos positivos do trabalho de colaboração profissional, os professores ressaltaram na esfera cognitiva, a construção de uma ponte entre a teoria e a prática, bem como a ampliação do universo de conhecimentos. Na esfera pessoal, destacaram a valorização da pessoa, de sua experiência (sua expertise) e o desenvolvimento de uma postura reflexiva, em diferentes modelos, níveis, lógicas e 
racionalidades. Trabalhar colaborativamente implica manter o entusiasmo, a despeito do cansaço, aliado ao desejo de transformar, de inovar. Quanto à esfera profissional, os professores apontaram o desenvolvimento do hábito de discutir e refletir sobre a prática do cotidiano. Em relação ao aspecto organizacional, enfatizaram o fortalecimento da comunidade escolar, a construção da cultura do trabalho coletivo e a construção/reflexão/ampliação do projeto educativo da escola.

Como aspectos negativos da experiência do trabalho em colaboração, na esfera pessoal, o professor Joshua destacou a não consideração de questões afetivo-emocionais. $\mathrm{Na}$ esfera profissional, a falta de articulação com profissionais da mesma área e a inexistência de propostas de trabalho que articulem significativamente profissionais de áreas diferentes. Na esfera organizacional, registraram-se a falta de impacto relevante e positivo das políticas de formação na ação docente e a desconexão das mesmas com a prática cotidiana do professor.

Faz diferença uma gestão escolar e coordenação pedagógica abertas ao diálogo, assim como a existência de um espaço/tempo voltado ao trabalho coletivo. Ressaltaram reduzidas ofertas de formação continuada específica para a área, escassez de incentivo profissional, falta e/ou inadequação de recursos. Na esfera profissional, o destaque foi para a questão do isolamento característico ao trabalho docente. Afirma o professor Joshua: "Eu não tenho encontrado gente do meu grupo que faça e que fale das coisas que eu quero estudar, para eu poder ir junto com eles."

\section{EIXO TEMÁTICO 3. A relação com o saber e a transformação da prática}

A professora Maria Fernanda diz: "a avaliação constante das ações desenvolvidas é um fator que contribui para a transformação da minha prática”. Essa avaliação foi destacada nos momentos de formação em contexto escolar e em processos internos de reflexão sobre a prática. Salienta a importância de aprendizagens construídas em sessões virtuais que mantêm em salas discursivas com professores da área, compartilhando êxitos e dificuldades, assim como, a reflexão sobre a realidade, ressaltando o ambiente escolar, o comportamento das pessoas e o contexto social dos alunos como uma necessidade.

Já para a professora Bibinha, a transformação da prática está especialmente condicionada ao trabalho colaborativo e, uma vez interligando os serviços de coordenação pedagógica e de gestão escolar, contribui para a articulação entre os 
profissionais da escola. Enfatiza que se o professor desenvolve seu trabalho de forma isolada, fica vencido pelo cansaço e pelas dificuldades no lidar com as novas gerações, além dos desafios referentes à motivação da aprendizagem. Para o professor Joshua, a (re)construção constante do saber é um dos aspectos a contribuir para a transformação da prática.

É preciso estar sempre atualizado e com predisposição para inovar. $O$ aspecto lúdico do ensino é motivação, tanto para aprender, como para ensinar. A reflexão sobre os motivos, as finalidades, os meios e a temporalidade da aprendizagem são significativos para a revisão da prática (Joshua).

Eixo temático 4. A relação com o saber e o desenvolvimento profissional

Para Charlot (2000), a relação com o saber pode ser superficial ou profunda. O grupo demonstrou desenvolver relação profunda com o saber, em diferentes dimensões e tempos de suas histórias de vida. Os professores expressaram que a busca constante pela construção do saber permite respostas às necessidades pessoais e profissionais. O que se percebe é que diferentes necessidades, quando combinadas ao processo reflexivo, expressam posturas mais críticas por parte dos professores quanto à missão que têm na sociedade. Evidenciaram que não é só a transformação da prática que basta, mas a relação desta com o próprio desenvolvimento profissional.

Sobre os saberes profissionais, Tardif (2002) assinala a identificação e a classificação desses na relação com as fontes sociais de aquisição e os modos de integração no trabalho docente. Assim é que entre as fontes sociais de aquisição estão: a família, o ambiente de vida, a educação no sentido lato, os professores, os estágios, os cursos complementares, a prática do ofício na escola, na sala de aula, a experiência dos pares etc. E, entre os modos de integração desses saberes no trabalho docente encontramse: a história de vida, formação e socialização pré-profissionais, formação e socialização profissionais na instituição de trabalho, prática do trabalho e socialização profissional.

Com base nas narrativas, a formação continuada encontra-se relacionada ao saber com a finalidade de aprender e de ensinar. Sendo assim, o sentido do processo de construção do saber tem o potencial de proporcionar experiências de transformação da prática. Apoiando-se em Day (2001) e nas narrativas, reafirmamos a tese de que o desenvolvimento profissional dos professores e a construção de sua identidade profissional dependem da relação que mantêm entre o saber e suas vidas pessoais e profissionais, assim como com as políticas e contextos escolares nos quais realizam as 
atividades docentes. E, quando gestores e coordenadores articulam o coletivo, a interação e socialização de informações propiciam maiores condições à construção do saber e ao desenvolvimento profissional.

EIXO TEMÁTICO 5. A dimensão tempo na relação com o saber

As narrativas destacaram uma outra dimensão, a do tempo na relação com o saber. Desde a infância, a dimensão tempo foi se construindo, se diferenciando e complexificando à medida que as experiências dos sujeitos (professores) proporcionaram (re)construções e transformações em seu universo cognitivo. Seja na escola, na universidade, em um ambiente formal de aprendizagem ou na informalidade de outros espaços sociais, a dimensão tempo foi permitindo outros contornos na relação com o saber, expressos nos objetivos, procedimentos e ações diferenciadas.

Em relação ao desenvolvimento profissional, consideramos fundamental a inclusão da dimensão tempo, tendo em vista possibilidades para a superação das condições e dos limites: [...] "Lógico que eu não proponho a mesma cópia do passado. Mas, posso ressignificar essa cópia e fazer uma aula muito diferente” (Joshua). “[...], mas, com o tempo, vamos aprendendo; aprendendo a lidar com os alunos” (Victória).

Os depoimentos dos professores demonstraram a importância de ultrapassar um outro tempo. Mesmo quando um professor decide regressar a uma prática anteriormente descartada, ou a um saber que considerava superado, há nessa ruptura um aspecto que transcende temporalmente. Tal perspectiva se justifica na dinâmica das interações e da construção do saber em diferentes momentos nas histórias de vida. Assim sinaliza Charlot (2000, p. 67):

Aprender é exercer uma atividade em situação: em um local, em um momento da sua história e em condições de tempo diversas, com a ajuda de pessoas que a ajudam a aprender. A relação com o saber é relação com o mundo, em um sentido geral, mas é, também, relação com esses mundos particulares - meios, espaços $[\ldots]$.

Portanto, nessa dimensão temporal do saber, alterações significativas ocorrem com impacto na relação do sujeito consigo mesmo - seu eu -, com os outros e com o mundo. Assim, para além das dimensões de identidade, epistêmica e social, o que propomos é que seja considerada a dimensão temporal na relação com o saber. 
Aos eixos temáticos anteriormente apresentados, encontram-se atreladas as categorias: reflexividade, profissionalidade, contextualidade e colaboratividade.

\section{REFLEXIVIDADE}

Aspectos da teoria de Schön (1995) nos ajudam a compreender, em especial, a consciência da ajuda ao outro e do aperfeiçoamento constante, a percepção positiva acerca da experiência de erros, da reflexão na ação, bem como do lidar com situações conflitivas a demandar reflexão e resolução. Com base em Alarcão (1996, 2001), compreende-se com maior profundidade a percepção de como os professores pensam a si próprios e como enfrentam as atividades em um processo heurístico, o qual é ao mesmo tempo, avaliativo e formativo. Criar condições para que os professores sejam reflexivos é um dos primeiros passos para a construção de uma escola reflexiva.

Foram também destacados o amor pela língua inglesa, a motivação, a responsabilidade, a postura investigativa, a busca por ser bom modelo para seus alunos, a construção de vínculos afetivos e duradouros, a constante superação de limites, a renovação das bases conceituais. Segundo Korthagen (2017), algumas dessas características, denominadas como 'nucleares', vinculam-se a um professor reflexivo. $\mathrm{O}$ autor destaca o fato de os professores reportarem-se à sua missão e aos seus ideais. Os professores revelaram, também, percepções que contribuem para a compreensão da reflexão como conceito estruturante da formação docente, não um conjunto de técnicas a serem ensinadas aos professores ou um conjunto de passos específicos. Para Zeichner (1993, 2008), a prática reflexiva se apresenta sob os enfoques: acadêmico, da eficiência social, desenvolvimentista e da reconstrução social. Esta última, como conceitualização recorrente nas narrativas.

\section{PROFISSIONALIDADE}

Considerando que os professores em formação continuada estão imersos em um processo de aprendizagem profissional, percebe-se nas narrativas alguma convergência da profissionalidade, no que se refere aos aspectos psicológicos que os afetam. Há, também, tendência nos relatos para atribuir ênfase aos aspectos organizacionais $e$ coletivos, o que reforça a visão de Ferreira (2009) de que a formação e a mudança se operam através da organização, valorizando-se os saberes experienciais, os contextos $e$ processos coletivos de trabalho. Marques et al. (2020) discutem que é preciso considerar 
os saberes experienciais como parte da formação docente e, uma vez que a legislação não considera isso, implica uma certa dose de "violência simbólica".

Para Day (2001), a aprendizagem profissional dos professores ocorre porque aprendem, naturalmente, ao longo de suas carreiras. Ou seja, o conceito de formação continuada, enquanto possibilidade de promoção de aprendizagem, é entendido como inerente à profissão docente. Logo, o processo formativo pressupõe a superação da lógica cumulativa. Não se trata de preencher lacunas da formação inicial, substituindo saber antigo por novo. Trata-se de (re) construir o saber que se diversifica e enriquece a praxis pedagógica, mediante a lógica de recomposição e de criatividade (CORREIA, 2005). Day (2001, p.17) esclarece que “[...] os professores não podem ser formados (passivamente). Eles formam-se (ativamente)." Nessa perspectiva, torna-se relevante à formação continuada a participação do professor na tomada de decisões sobre o sentido e os processos de sua própria aprendizagem. As narrativas corroboram essa teorização.

Enfim, os professores evidenciam que para as modalidades de formação garantirem aprendizagem profissional, é preciso que a própria organização aprenda a valorizar as experiências e saberes docentes, os contextos, os processos coletivos e criar condições de participação destes, nas tomadas de decisão. Segundo Ferreira (2009, p. 218), “[...] A formação e a mudança se operam através da organização, não se tratando [...] de mudar pessoas supostamente carentes, mas as organizações e os seus problemas".

\section{CONTEXTUALIDADE}

A aproximação entre os contextos de trabalho e os contextos de formação, segundo Correia (2005, p. 66) permite reequacionar o papel atribuído à experiencialidade e à cientificidade no campo formativo, assim como "impulsionar uma formação que promova aproximação crítica, interpelante, funcionalmente 'desadaptada' das relações instituídas no trabalho e preocupada com a requalificação dos coletivos de trabalho." Ao confrontar os resultados com as teorizações do autor compreende-se que os professores expressam aproximação maior com a lógica de recomposição, ou seja, a formação se apoia no patrimônio experiencial produzido ao longo do tempo e que, como no trabalho criativo do artesão, integra elementos novos, enriquecendo e diversificando, não substituindo conhecimentos.

Observou-se que os contextos educativos formais evidenciam profundas instabilidades que traduzem complexidade de percepções, de representações e de relações 
vividas cotidianamente no interior da escola, conforme Pereira e Mouraz (2015). Lopes et al. (2011) corroboram, apontando as vantagens de uma maior descentralização da oferta formativa, com maior proximidade aos contextos de trabalho, melhor gestão do tempo de formação e maior implicação dos próprios professores.

\section{COLABORATIVIDADE}

Estudos de Forte e Flores (2012) apontam para experiências de práticas colaborativas com periodicidade esporádica, de caráter formal, no desenvolvimento de projetos pontuais, numa lógica de imposição. Alertam para a necessidade da promoção de práticas formativas em contexto de trabalho como estratégia para proporcionar o desenvolvimento profissional e desafiar culturas profissionais marcadas pelo isolamento. Nosso estudo aponta para algumas similaridades. Entretanto, há ausência de referências à lógica de imposição, apesar de o processo ser realizado na jornada de trabalho, o que sugere caráter de compulsoriedade.

Sobre as situações de colaboração foram destacados nos relatos quatro tipos de atividades recorrentes: 1) socialização de práticas relevantes; 2) socialização de problemas enfrentados; 3) planejamento de práticas em conjunto, a partir da reflexão sobre as potencialidades do contexto; 4) socialização de estudos, objetivando fundamentação mais aprofundada de vários aspectos.

\section{CONSIDERAÇÕES FINAIS}

O presente estudo considera que o processo de formação continuada contempla alguns avanços e possibilidades, mas, ao mesmo tempo, entraves que obstaculizam a sua efetividade, sobretudo no que se refere à relação saber e prática que se pretende transformadora. As interações entre os diferentes segmentos que compõem a escola, bem como as lógicas de formação por eles construídas têm demonstrado capacidade de ressignificar as dinâmicas de construção do saber. Para Pereira (1999), as racionalidades explicitam diferenciados níveis de complexidade. Assim é que neste estudo, há momentos em que se manifesta uma racionalidade técnica, em outros, uma racionalidade prática. A racionalidade crítica também é manifestada com certa frequência e, em alguns momentos, voltada às questões emancipatórias. Na percepção dos professores, o fato da formação continuada ser desenvolvida em contextos de trabalho traz em si grande complexidade. 
Com as mudanças ocorridas nos últimos anos, a percepção dos professores sobre o processo de formação continuada encontra-se mais vinculada à burocratização do ensino, às exigências legais e avaliações externas, sobretudo em conformidade às demandas governamentais. É possível também afirmar que a formação continuada tem contribuído de forma decisiva para a transformação da prática.

Nesse sentido, a colaboração profissional ganha destaque, em alguns casos, pela presença marcante; em outros, pela ausência sentida. As percepções dos professores acerca da construção do saber revelam pontos significativos relacionados às dinâmicas de colaboração dentro e fora do contexto escolar, como reafirmam Flores (2017), Forte e Flores $(2012,2014)$. No que diz respeito à relação com o saber construído nas interações, registra-se, na percepção dos professores, a presença das dimensões social, identitária ou epistêmica. No entanto, para Charlot (2000) tais dimensões na relação com o saber são inseparáveis. O que pode variar é a predominância de uma ou outra, em determinadas situações. Argumentamos relevância à inclusão da dimensão temporal na relação com o saber.

Outro ponto diz respeito às descontinuidades apontadas em algumas narrativas. Segundo Pereira (1999, p. 32): “As práticas formativas articulam-se com as racionalidades de produção de inovações e são marcadas por descontinuidade no tempo e no espaço, entre a teoria e a prática e descontinuidade entre as dimensões profissional e pessoal da formação."

As tensões vividas pelos professores também foram mencionadas. Assim é que quando o Estado delega às escolas uma "pretensa" autonomia para a formação docente (incluindo a formação continuada) responsabiliza os profissionais da educação pelos resultados, em meio a um quadro de desvalorização profissional, precarização das condições de trabalho e, ainda, atribuindo-lhes programas pouco flexíveis. Para Charlot (2014), há nessas tensões e obrigatoriedades a possibilidade de criação de mecanismos de fortalecimento e de resistência por parte da comunidade escolar, a partir da reflexão de suas necessidades e potencialidades. Segundo Charlot (2008). "O professor é um trabalhador da contradição".

A construção de uma escola reflexiva, como afirma Alarcão (1996) - uma comunidade aprendente -, seria uma possibilidade de transformação e inovação para além dos aspectos pedagógicos, não só real e viável, mas desejável. Fica evidente nas narrativas analisadas, que o processo de formação continuada ainda distancia o professor da abertura 
para o aprender e para (re)construir o saber, assim como da condição crítica que o conduz a uma prática emancipatória. Porém, quando a formação transcende os aspectos de obrigatoriedade e normativos, os professores manifestam força de resistência e de mobilização. Compreende-se assim que a formação continuada que se almeja transformadora vincula-se à mobilização em direção ao saber, bem como à conscientização por docentes e gestores das contradições das relações sociais dentro e fora do contexto escolar.

\section{REFERÊNCIAS}

ALARCÃO, I. Formação reflexiva de professores: estratégias de supervisão. Porto: Porto Editora, 1996.

ALARCÃO, I. Escola reflexiva e nova racionalidade. Porto Alegre: Artmed, 2001.

AMADO, J. Manual de investigação qualitativa em educação. Coimbra: Imprensa da Universidade de Coimbra, 2014.

BOGDAN, R.; BIKLEN, S. K. Investigação qualitativa em educação: uma introdução à teoria e aos métodos. Porto: Porto Editora, 1994.

CHARLOT, B. Da relação com o saber: elementos para uma teoria. Porto Alegre: Artes Médicas Sul, 2000.

CHARLOT, B. Relação com o saber, formação dos professores e globalização: questões para educação hoje. Porto Alegre: Artmed, 2005.

CHARLOT, B. O professor na sociedade contemporânea: um trabalhador da contradição. Revista da FAEEBA - Educação e Contemporaneidade, Salvador, v. 17, n. 30, p. 1731, jul./dez. 2008. Disponível em:

https://www.revistas.uneb.br/index.php/faeeba/issue/view/227/126. Acesso em:12 dez. 2020.

CHARLOT, B. Da relação com o saber às práticas educativas. São Paulo: Cortez, 2014.

CORREIA, J. A. A formação da experiência e a experiência da formação num contexto de crise do trabalho. In: CANÁRIO, R.; CABRITO, B. (Eds.). Educação e formação de adultos: mutações e convergências. Lisboa: Educa, 2005. p. 61-72.

DAY, C. Desenvolvimento profissional de professores: os desafios da aprendizagem permanente. Porto: Porto Editora, 2001.

FERREIRA, F. As lógicas da formação: para uma conceção de formação contínua de professores como educação de adultos. In: FORMOSINHO, J. (Ed.). Formação de 
professores: aprendizagem profissional e acção docente. Porto: Porto Editora, 2009.p. 201-220.

FLORES, M.A. How do teachers learn in the workplace? Findings from an empirical study carried out in Portugal. Journal of In-Service Education, v.31, n.3, p.485-508, 2005. Disponível em:

https://www.tandfonline.com/doi/abs/10.1080/13674580500200290. Acesso em: 29 dez. 2020.

FLORES, M. A. Culturas profissionais e promoção do sucesso escolar. In: CABRAL, I.; MATIAS ALVES, J. (Coords.). Da construção do sucesso escolar: uma visão integrada. Vila Nova de Gaia: Fundação Manuel de Leão, 2017. p. 85-114.

FORTE, A. M.; FLORES, M. A. Potenciar o desenvolvimento profissional e a colaboração docente na escola. Cadernos de Pesquisa, v. 42, n. 147, p. 900-919, 2012. Disponível em:http://dx.doi.org/10.1590/S0100-15742012000300014.Acesso em: 17 dez. 2020.

FORTE, A. M.; FLORES, M. A. Teacher collaboration and professional development in the workplace: a study of Portuguese teachers. European Journal of Teacher Education, v. 37, n. 1, p. 91-105, 2014. Disponível em: https://www.researchgate.net/publication/262951824. Acesso em: 10 jan.2021.

GATTI, B. A. (Coord.). Professores do Brasil: impasses e desafios. Brasília: UNESCO, 2009.

GOODSON, I. Currículo, narrativa e o futuro social. Revista Brasileira de Educação, v.12, n. 35, p. 241-252, 2007. Disponível em:

http://dx.doi.org/10.1590/S1413-24782007000200005. Acesso em: 22 dez.2020.

KORTHAGEN, F. Inconvenient truths about teacher learning: towards professional development 3.0. Teachers and Teaching: theory and practice, v. 23, n. 4, p. 387-405, 2017. Disponível em:

https://www.tandfonline.com/doi/full/10.1080/13540602.2016.1211523.

Acesso em: 13 jan. 2021.

LIMA, J. A.; PACHECO, J. A. Fazer investigação: contributos para a elaboração de dissertações e teses. Porto: Porto Editora, 2006.

LOPES, A. Libertar o desejo, resgatar a inovação: a construção de identidades profissionais docentes. Lisboa: Instituto de Inovação Educacional, 2001.

LOPES, A.; et al. Formação contínua de professores 1992-2007: contributos de investigação para uma apreciação retrospectiva. Porto: Livpsic, 2011.

MARQUES, W. R.; FERREIRA, D. J. L.; CUTRIM, D. S. P.; VIANA, M. N. G.; FREITAS, M. D. de; COSTA, R. C.; ROCHA, L. F. de B. V.; SOARES, H. A. Profissionalidade docente: Saber e busca de reconhecimento. In: Braz. J. of Develop., Curitiba, v. 6, n.12, p.97692-97711 dec. 2020. 
MINAYO, M. C. Pesquisa social: teoria, método e criatividade. Petrópolis: Vozes, 2011.

PEREIRA, F. Transformação educativa e formação contínua de professores: equívocos e possibilidades.1999. Dissertação (Mestrado em Ciências da Educação) Universidade do Porto, Porto - Portugal,1999.

PEREIRA, F.; MOURAZ, A. Crise da educação escolar e percepções dos professores sobre o seu trabalho: identidade profissional e clima de escola em análise. Educação em revista, v.31, n.1, p.115-138, jan./mar. 2015.Disponível em: https://www.redalyc.org/pdf/3993/399360941006.pdf. Acesso em: 11 jan.2021.

SÃO LUIS (cidade). PREFEITURA MUNICIPAL. SECRETARIA DE EDUCAÇÃO. Formação dos educadores: uma ação estratégica e transversal às políticas públicas para a educação. São Luís: Prefeitura Municipal. Secretaria de Educação, 2004.

SCHÖN, D. Reflective practice: its implications for classroom, administration and research. Parkville, Australia: University of Melbourne, 1995.Disponível em: https://uni.edu/ eastk/109/sp08/270905.pdf. Acesso em: 12 dez. 2020.

TARDIF, M. Saberes docentes e formação profissional. Petrópolis: Vozes, 2002.

ZEICHNER, K. A formação reflexiva de professores: ideias e práticas. Lisboa: Educa, 1993.

ZEICHNER, K. Uma análise crítica sobre a "reflexão" como conceito estruturante na formação docente. Educação e Sociedade, v. 29, n. 103, p. 535-554, 2008.

Disponível em: https://www.scielo.br/pdf/es/v29n103/12.pdf. Acesso em: 19 jan.2021.

Recebido em: 01/10/2021

Aprovado em: 25/10/2021

Publicado em: 27/10/2021

Notas

i Este artigo é um recorte da pesquisa desenvolvida no Programa de Doutorado em Ciências da Educação, Universidade do Porto, Portugal.

ii Este trabalho foi apoiado por fundos nacionais, através da Fundação para a Ciência e a Tecnologia, IP, no âmbito do programa estratégico do CIIE - Centro de Investigação e Intervenção Educativas da Universidade do Porto [ref. ${ }^{a}$ UID/CED/00167/2019]. 